\title{
Supporting Materials for: Glassy protein dynamics and gigantic solvent reorganization energy of plastocyanin
}

\author{
David N. LeBard and Dmitry V. Matyushov \\ Center for Biological Physics, Arizona State University, PO Box 871604, Tempe, AZ 85287-1604
}

Figure $\mathrm{S} 1$ shows the $\mathrm{Cu}-\mathrm{O}$ distribution function calculated for Ox and Red states of PC at 285 and 310 K. Figure S2 shows the vibrational density of states of plastocyanin (PC) calculated from quasi-harmonic analysis implemented in Amber8.0. The peak of the density of vibrational states at about $36 \mathrm{~cm}^{-1}$ is in agreement with the low-frequency vibrations with ca. $33 \mathrm{~cm}^{-1}$ seen in Raman spectra of plastocyanin. ${ }^{1}$

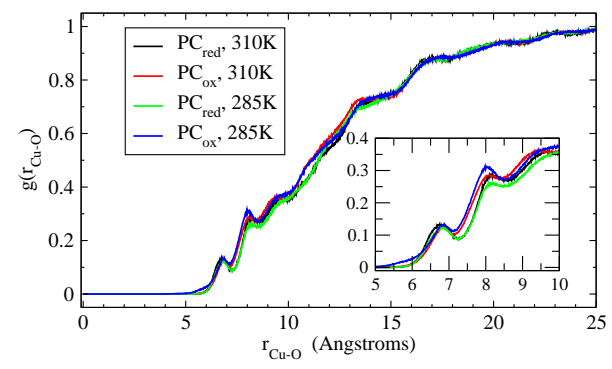

FIG. S1: Radial distribution function between plastocyanin's copper atom and the water's oxygen.

Figure S3 presents an example of Stokes shift correlation functions calculated from 400 ps and a 10 ns windows. The
Stokes shift functions are fitted to eq (14) to extract the fast and slow relaxation components. The hundreds of picoseconds tail seen in the $10 \mathrm{~ns}$ average is completely lost for the narrow time window. The value for $\beta$ also changes from $\beta=0.69$ characteristic of heterogeneous dynamics to $\beta=1$ of the exponential decay when the observation window is narrowed.

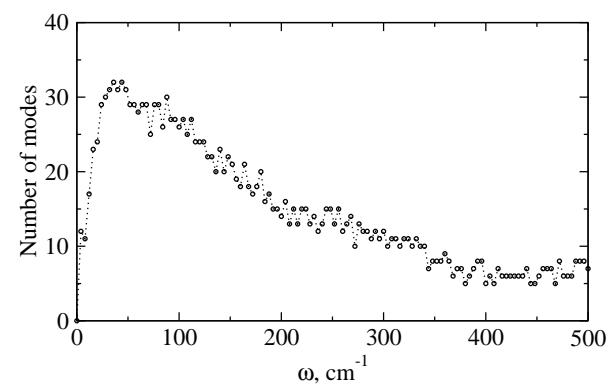

FIG. S2: Vibrational density of states of plastocyanin in TIP3P water at $310 \mathrm{~K}$.
${ }^{1}$ Nakashima, S.; Nagasawa, Y.; Seike, K.; Okada, T.; Sato, M.; Kohzuma, T. Chem. Phys. Lett. 2000, 331, 396.

${ }^{2}$ Duan, Y.; Wu, C.; Chowdhury, S.; Lee, M. C.; Xiong, G.; Zhang, W.; Yang, R.; Cieplak, P.; Luo, R.; Lee, T.; Caldwell, J.; Wang, J.; Kollman, P. J. Comp. Chem. 2003, 24, 1999-2012.

${ }^{3}$ Ullmann, G. M.; Knapp, E.-W.; Kostić, N. M. J. Am. Chem. Soc.
1997, 119, 42-52.

${ }^{4}$ Solomon, E.; Szilagyi, R.; DeBeerGeorge, S.; Basumallick, L. Chem. Rev. 2004, 104, 419-458.

5 Kerpel, J. O. D.; Ryde, U. Proteins: Structure, Function, and Genetics 1999, 36, 157-174. 


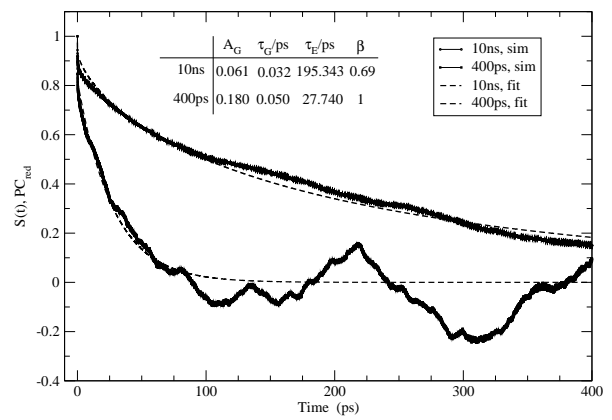

FIG. S3: Stokes shift correlation function for reduced state at $310 \mathrm{~K}$ using a $400 \mathrm{ps}$ and $10 \mathrm{~ns}$ windows. The dashed lines are fits to eq (14) with the fitting parameters displayed in the plot.

TABLE S1: Charging scheme of plastocyanin for MD simulations. The $\Delta z_{j}$ charge differences refer to the change from red to ox.

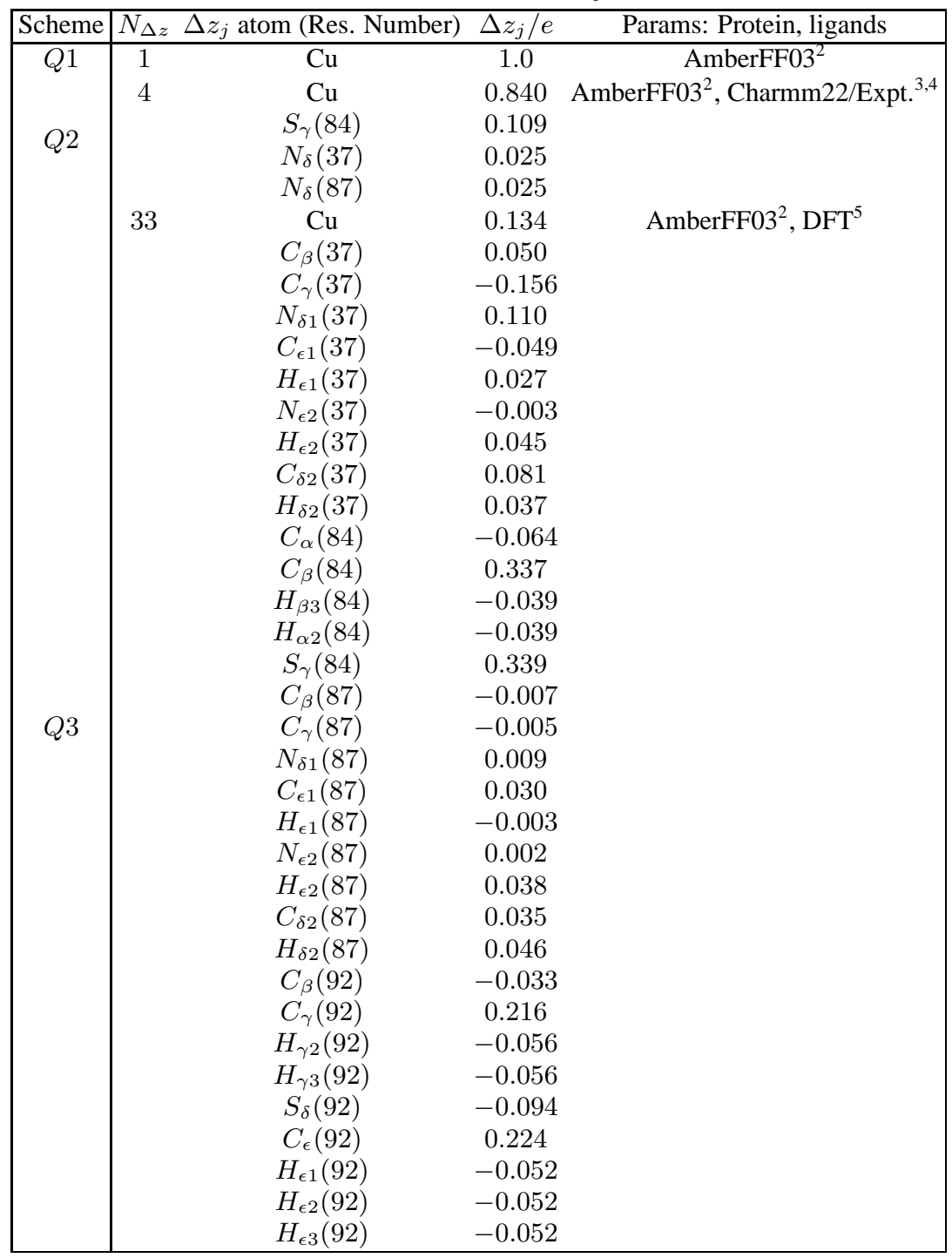

